DOI 10.19195/2084-2546.25.2

\title{
Homenaje al profesor Piotr Sawicki
}

El día 11 de mayo de 2017 tuvo lugar en el Oratorium Marianum, una de las salas barrocas más representativas de la Universidad de Wrocław, una jornada de homenaje al profesor Piotr Sawicki, organizada por el Departamento de Filología Románica y la Escuela Superior de Filología de Wrocław. El acto, celebrado con motivo del $70^{\circ}$ cumpleaños del maestro, congregó a más de ochenta personas entre autoridades, compañeros, familiares, antiguos alumnos y amigos del catedrático. Destacó la presencia del rector de la Universidad de Wrocław, Prof. Dr. Adam Jezierski, de la Prof. Dra. Iwona Bartoszewicz de la Universidad de Wrocław, del rector de la Escuela Superior de Filología, Prof. Dr. Norbert Morciniec, del representante de la Embajada de España, D. Santiago Sierra González del Castillo, del cónsul honorario de España en Wrocław, D. Jesús García-Nieto Moreno, y de los representantes de algunas de las instituciones con las que el profesor Sawicki ha colaborado estrechamente a lo largo de su carrera; entre otros, asistieron el Prof. Dr. Marcin Cieński, decano de la Facultad de Filología de la Universidad de Wrocław, la Prof. Dra. Maria Falska, directora del Departamento de Estudios Hispánicos de la Universidad Maria Curie-Skłodowska de Lublin, la Prof. Dra. Karolina Kumor de la Universidad de Varsovia, la Prof. Dra. Anna Sawicka de la Universidad Jagellónica o la Prof. Dra. Jitka Smičeková de la Universiad de Ostrava.

La inauguración corrió a cargo de la Prof. Dra. Beata Baczyńska, directora del Departamento de Filología Románica, que dio la bienvenida a todos los presentes y, en especial, al profesor Piotr Sawicki. Después tomó la palabra el decano de la Facultad de Filología, Prof. Dr. Marcin Cieński, que presentó una semblanza del homenajeado: "El profesor Piotr Sawicki es un investigador polivalente y admirado, estudioso de la literatura, historia, cultura y lengua españolas, autor de trabajos sobre la literatura contemporánea española y las literaturas en lenguas minoritarias, el cine español, las relaciones históricas entre Polonia y España, así como la fraseología y paremiología comparada". Tras describir la brillante trayectoria académica del profesor Sawicki, concluyó: "El profesor Piotr Sawicki es para la comunidad de los hispanistas polacos una leyenda viva y en sí mismo una institución. Ha participado activamente en el proceso de desarrollo y consolidación de esta comunidad como tutor y reseñador de tesis doctorales y como miembro de jurados en los procesos de concesión de los títulos académicos de doctor habilitado y de profesor 
catedrático. Este hecho ha contribuido notablemente a la firme posición del hispanismo de la Universidad de Wrocław en el mapa académico de Polonia".

A continuación el rector de la Universidad de Wrocław intervino para condecorar al catedrático con la medalla de la Universidad de Wrocław y felicitarle por sus logros y su trabajo. El representante de la Embajada de España, D. Santiago Sierra González del Castillo, pronunció un discurso de agradecimiento, transmitiendo un saludo muy afectuoso del Embajador de España y subrayando la participación activa del profesor Sawicki en el desarrollo de las relaciones entre ambos países y sus centros académicos. D. Santiago Sierra señaló la importancia de los estudios históricos y literarios del catedrático y habló sobre la literatura de exilio, uno de los temas explorados por el profesor Sawicki y el tema principal del congreso "Destierro y destiempo: exilios hispanos y polacos" que fue inaugurado ese mismo día en el Departamento de Filología Románica.

El rector Norbert Marciniec tomó la palabra para reconocer los éxitos del homenajeado y su contribución a la creción y el crecimiento de la Filología Española en Wrocław, en Cracovia y en Ostrava. "Hay un apodo relacionado de manera muy estrecha con tu apellido: Eres el padre de la iberística polaca", comentó el rector, dirigiéndose a su amigo. Finalmente, la Prof. Dra. Karolina Kumor leyó una carta de agradecimiento y felicitaciones escrita por las autoridades del Departamento de Estudios Ibéricos e Iberoamericanos y de la Facultad de Neofilología de la Universidad de Varsovia. Como colofón, intervino el profesor Sawicki para agradecer el acto, la medalla y la presencia de los que se reunieron en el Oratorium Marianum ese día. El homenajeado habló de su propia experiencia como estudiante e investigador y de los que le guiaron y animaron en su trayectoria académica: el Prof. Dr. Jerzy Falicki y el Prof. Dr. Józef Heistein.

A continuación intervino Marta Misztal, una organista especializada en el órgano ibérico, la música antigua italiana, alemana y polaca que preparó para el homenajeado, su amigo, un concierto de música barroca. A ese recital, muy emocionante y fuertemente aplaudido, le siguió una mesa redonda sobre la investigación conducida por el profesor Sawicki, sus éxitos y logros didácticos, y la historia de la Filología Española en Wrocław. La Dra. Małgorzata Kolankowska de la Escuela Superior de Filología presidió esta sesión, alentando a sus participantes a presentar al público, a través de una conversación interesante y animada, los estudios literarios, el trabajo didáctico en Wrocław y en Ostrava y la actividad periodística del homenajeado. La Prof. Dra. Magda Potok, la Prof. Dra. Ewa Nawrocka, la Prof. Dra. Justyna Ziarkowska y el Dr. Jan Mlcoch, colegas y discípulos del profesor Sawicki, subrayaron la importancia de la contribución del homenajeado al desarrollo de varios centros académicos en Polonia y Ostrava y de su investigación. Como subrayó Magda Potok, "el profesor escribe la mayor parte de sus estudios en polaco, lo cual hace que los lectores de la literatura española, que cuenta con cada vez más traducciones, tengan acceso a trabajos críticos. Escribiendo él mismo en polaco, 


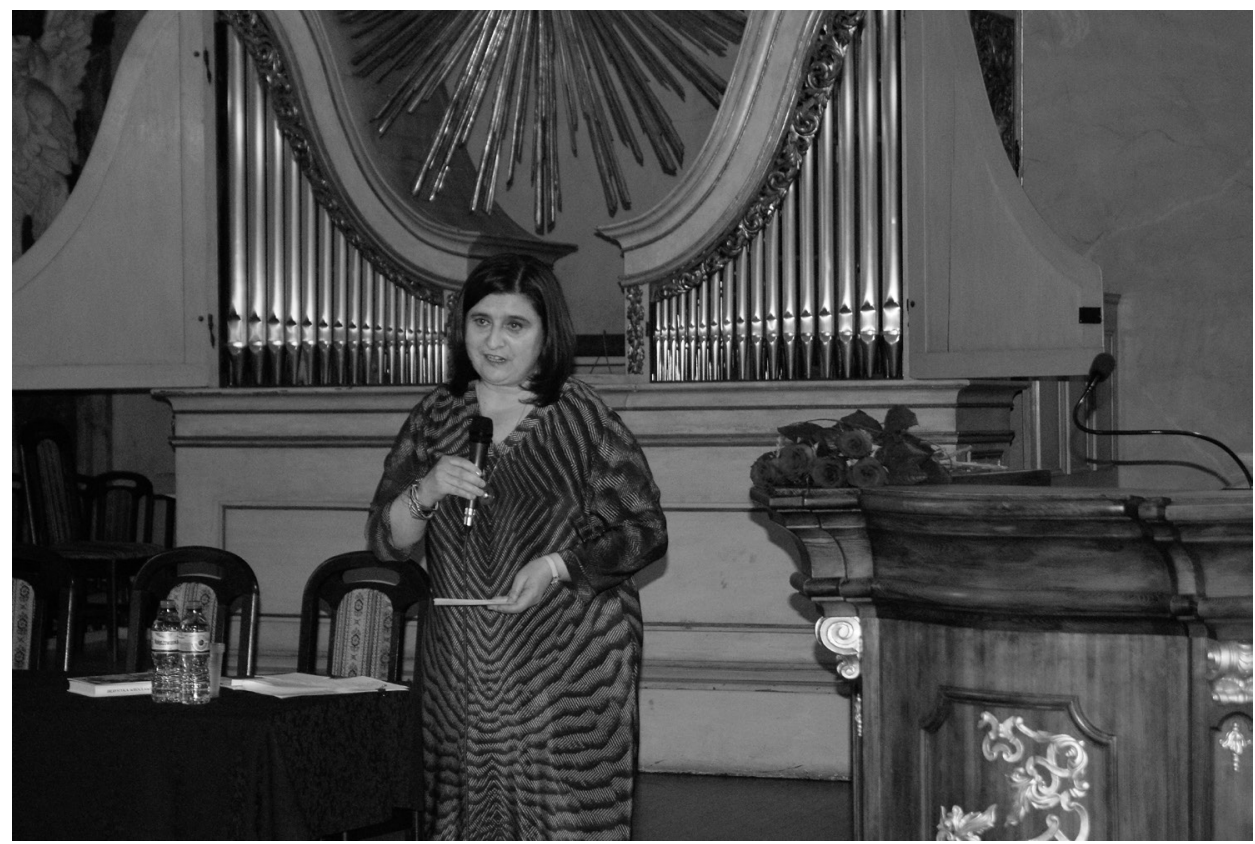

La directora del Departamento de Filología Románica, Prof. Dra. Beata Baczyńska, durante la inauguración del acto

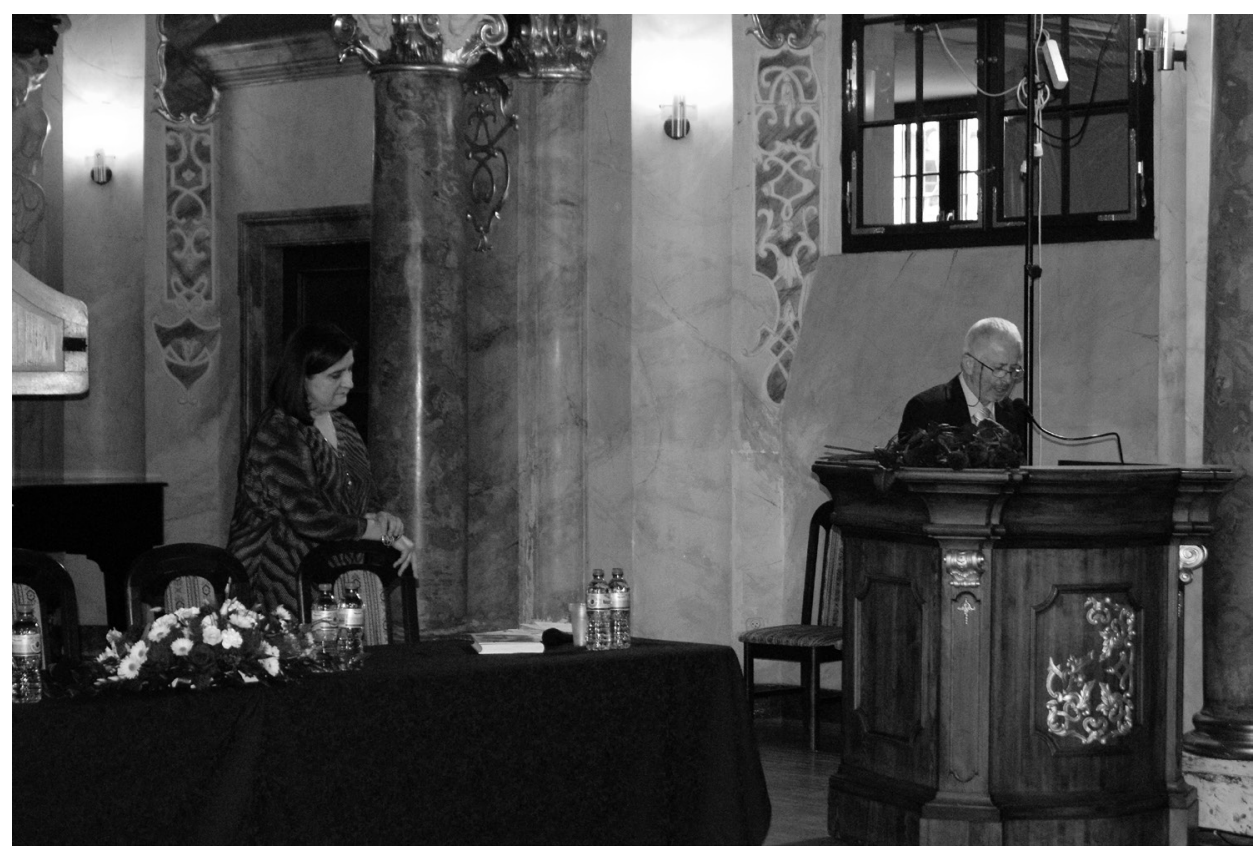

El decano de la Facultad de Filología, Prof. Dr. Marcin Cieński, y la directora del Departamento de Filología Románica, Prof. Dra. Beata Baczyńska 


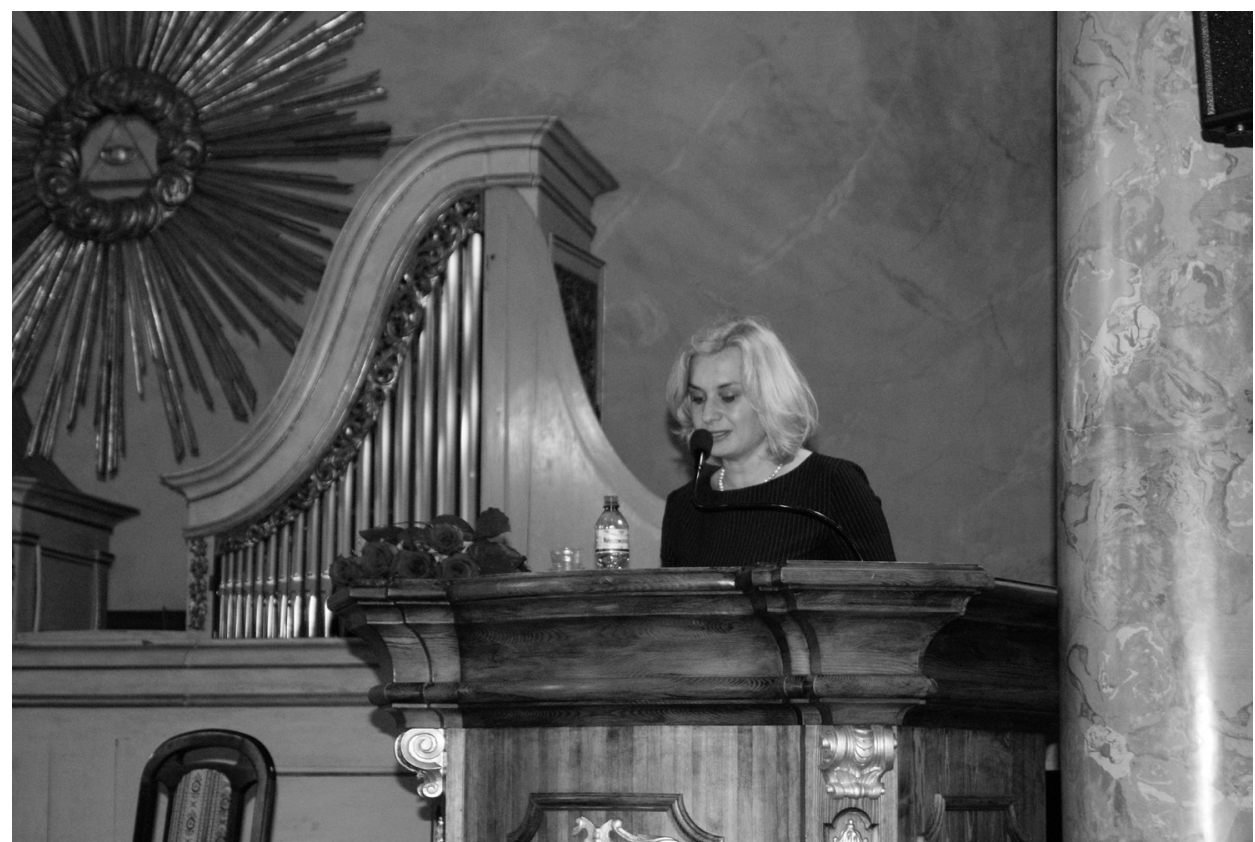

La Dra. Małgorzata Kolankowska presidiendo la mesa redonda dedicada a la investigación, éxitos y logros didácticos del homenajeado

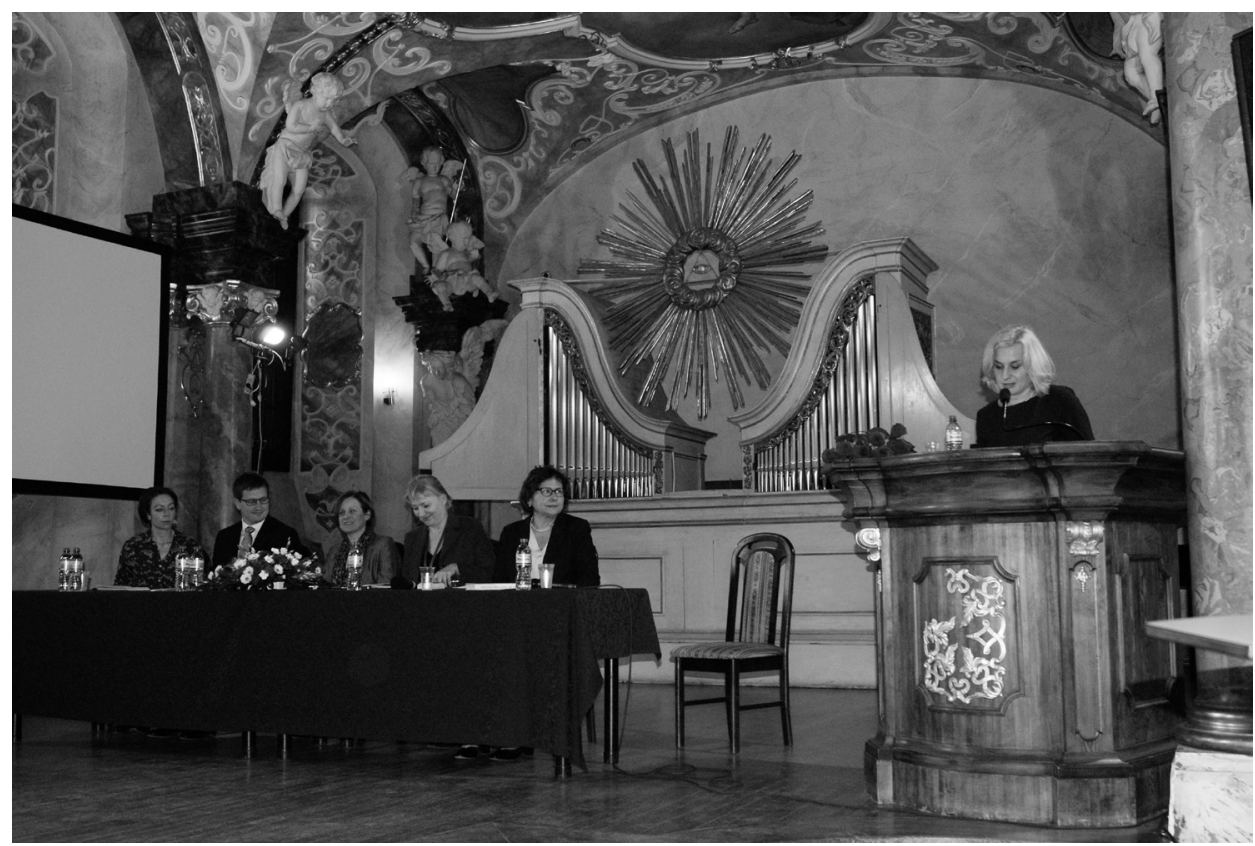

La mesa redonda: el Dr. Jan Mlcoch, la Prof. Dra. Magda Potok, la Prof. Dra. Justyna Ziarkowska y la Prof. Dra. Ewa Nawrocka 


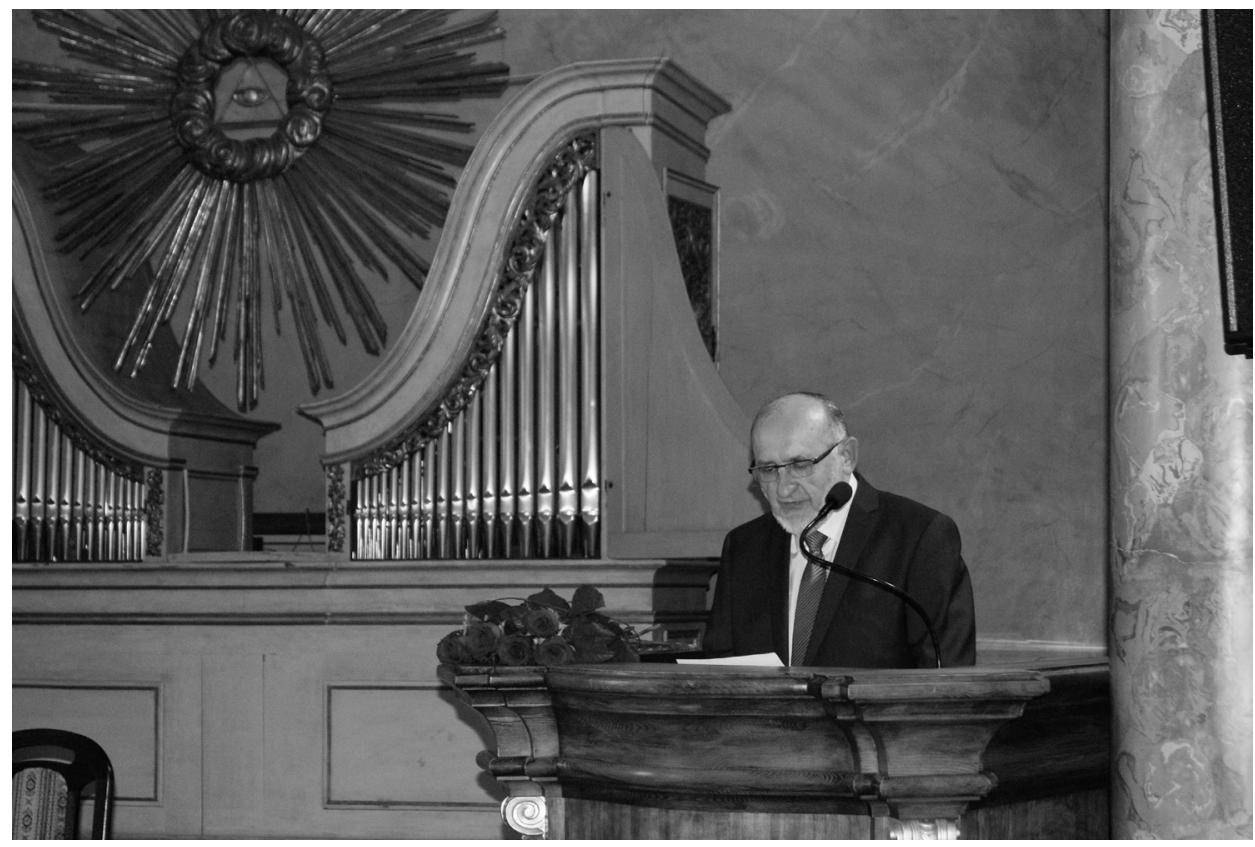

El homenajeado, Prof. Dr. Piotr Sawicki, habla y recuerda el pasado

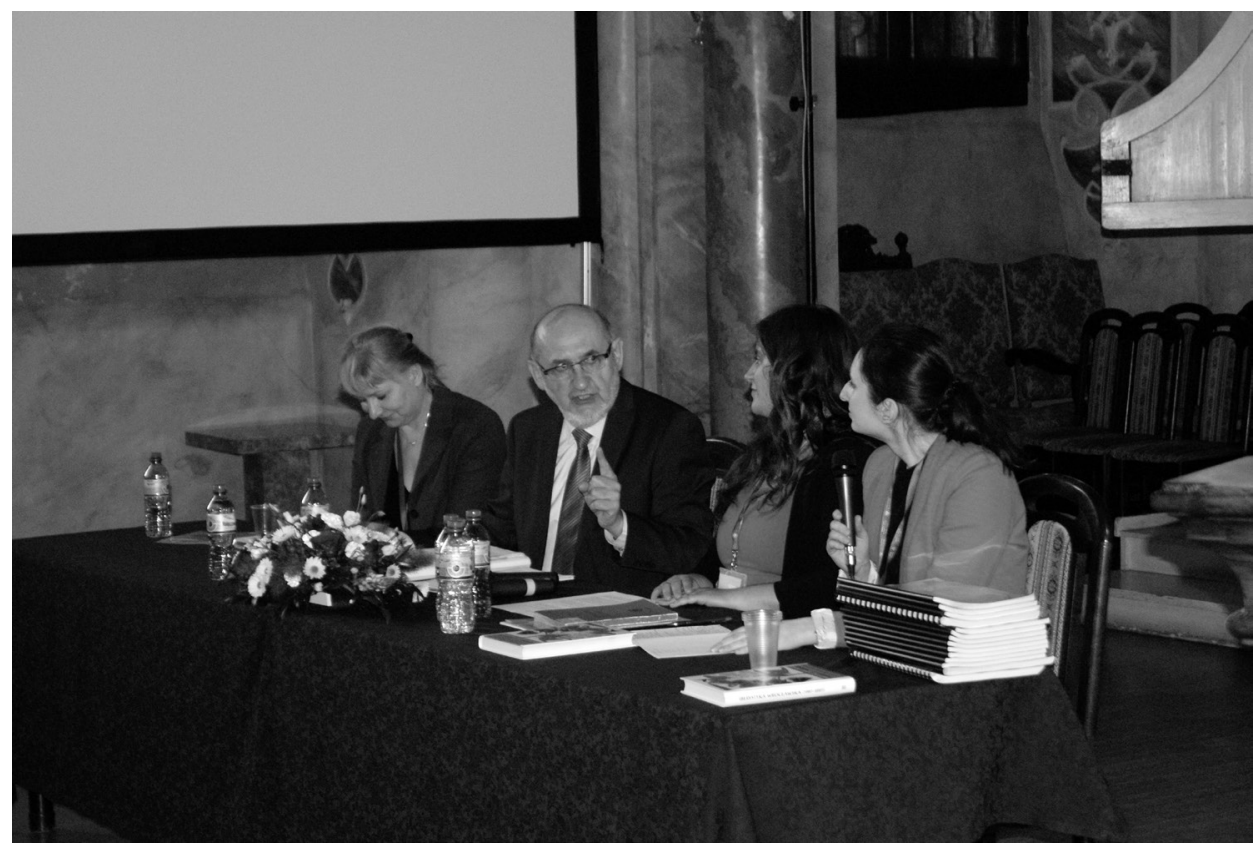

La presentación del libro Iberystyka Wroctawska (1967-2007). Ilustrowany przewodnik retrospektywny, de Piotr Sawicki, Marta Minkiewicz y Ania Olchówka 


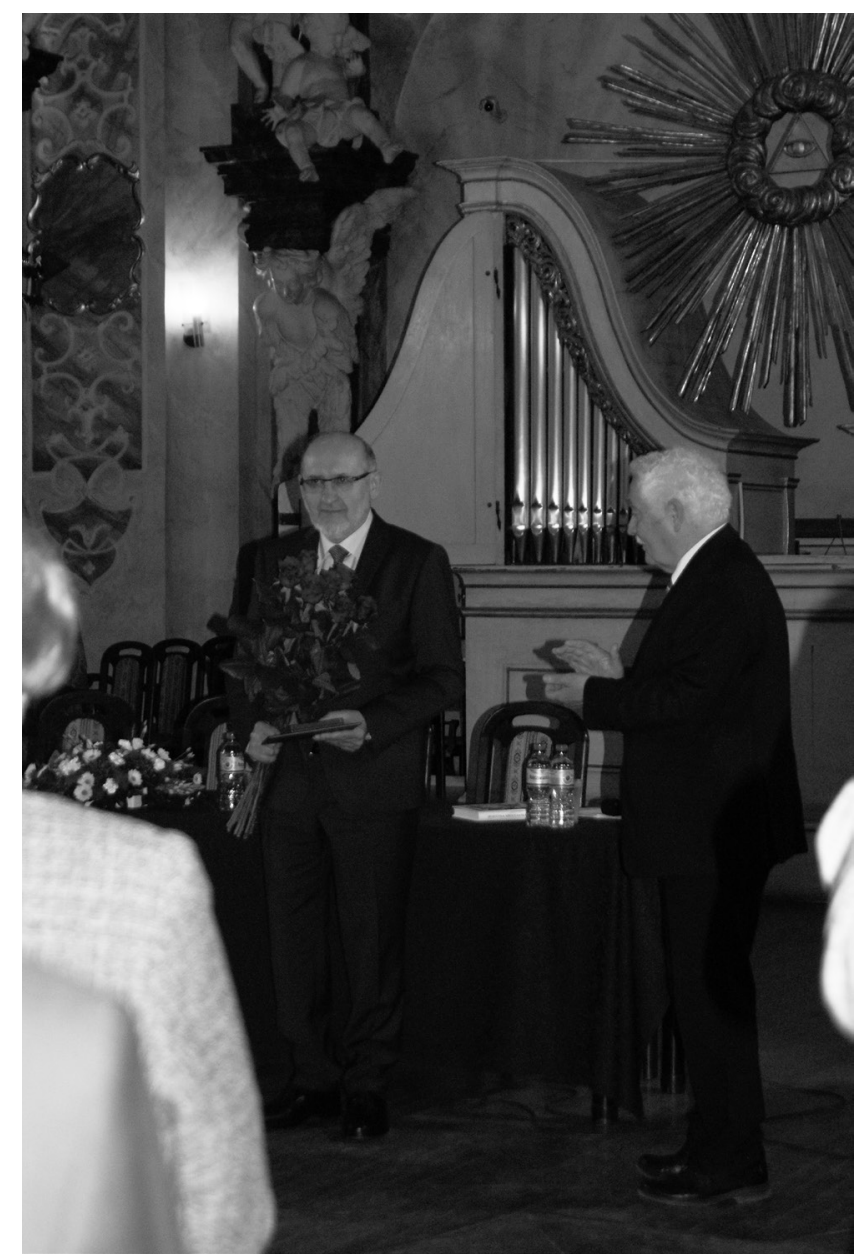

El rector, Prof. Dr. Adam Jezierski, condecorando al homenajeado con la medalla de la Universidad de Wrocław

el profesor empezó una gran tradición, sobre todo en Wrocław, de publicar los trabajos de investigación en polaco. Y es el polaco que merece también un comentario, porque se trata de un lenguaje bello, fructífero y pintoresco, a la vez que ligero y matizado por un sentido del humor sútil”.

A continuación se compartió, en un ambiente de celebración y alegría, una copa de vino, y el homenajeado invitó a los participantes de la jornada a asistir a la presentación de su libro, escrito en colaboración con Marta Minkiewicz y Anna Olchówka: Iberystyka wrocławska (1967-2007). Ilustrowany przewodnik retrospektywny. Esta crónica del Departamento de Hispánicas de la Universidad de Wrocław sirvió como pretexto para comentar los momentos buenos y malos, divertidos y tristes de la historia de la iberística en Wrocław. El profesor Sawicki, dotado de una excelente memoria y rodeado de documentos y foto- 


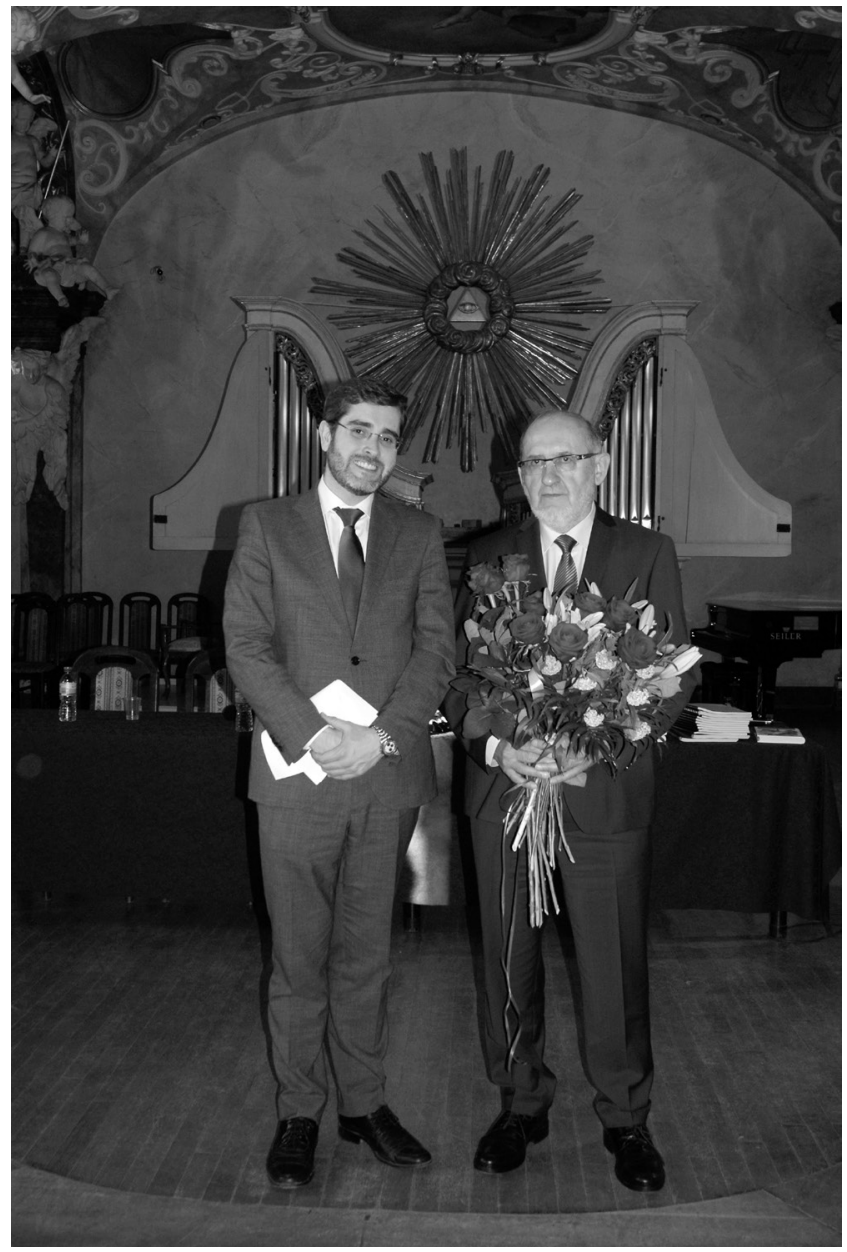

El Prof. Dr. Piotr Sawicki con el representante de la Embajada de España, D. Santiago Sierra González del Castillo

grafías de la época, en un diálogo con la Prof. Dra. Justyna Ziarkowska y la Dra. Agata Draus-Kłobucka, ofreció al público una charla excepcional, repleta de anécdotas, chistes y poemas de los estudiantes. Siempre con una sonrisa medio benevolente, medio maliciosa, relató sus propios esfuerzos y el de sus compañeros y mentores para crear, entre los años 1976 y 1991, el Departamento de Hispánicas, una tarea sorprendentemente ardua, pero de un gran significado para todos los presentes ese día en el Oratorium Marianum. Este tema, y otros muchos relacionados con el homenaje del profesor Sawicki, fueron continuados después durante una cena que se ofreció a los invitados.

Agata Draus-Kłobucka (Uniwersytet Wrocławski) 